\title{
ATENDIMENTO EDUCACIONAL ESPECIALIZADO: O QUE PENSAM PROFESSORES SOBRE SUA ATUAÇÃO E FORMAÇÃO
}

\author{
Marco Antonio Melo Franco ${ }^{(*)}$ \\ Cristiane Dias Ribeiro ${ }^{(* *)}$ \\ Fabiana Nascimento de Almeida ${ }^{(* * *)}$
}

\section{INTRODUÇÃO}

Temos visto na atualidade o crescimento de políticas públicas voltadas para o acesso e a permanência de crianças com deficiência e outras necessidades específicas no ensino regular. Nos últimos 15 anos o ingresso de alunos público-alvo da educação especial tem aumentado, consideravelmente, nas escolas regulares tornando visível a insegurança dos professores que não se veem preparados para atuar com esse público. Com base nesse contexto, percebemos que os professores, em sua formação, não estão aptos a lidar com a diversidade, visto que a formação inicial nem sempre consegue romper com o modelo de ensino tradicional e se mantém produzindo práticas excludentes.

Por outro lado, é possível identificar que, mesmo lentamente, essa realidade vem se transformando e as práticas inclusivas vêm acontecendo no ambiente escolar. Uma delas, resultado de políticas públicas, são as ações realizadas nas salas multifuncionais que disponibilizam recursos e métodos para o atendimento pedagógico de alunos público-alvo da educação especial em escolas de ensino regular.

Entendendo a importância desses espaços de ensino para a aprendizagem de alunos com necessidades especiais o professor que atua, neste ambiente, precisa de uma formação voltada para o atendimento educacional especializado aos alunos público-alvo da educação especial. Para qualificar a formação desses profissionais da educação básica, as instituições de ensino superior

\footnotetext{
${ }^{(*)}$ Professor associado do Departamento de Educação e do Programa de Pós -graduação em Educação da Universidade Federal de Ouro Preto. Membro do Observatório Internacional de Inclusão, Interculturalidade e Inovação Pedagógica/OIIIIPe (Coordenador OIIIIPe/UFOP). E-mail: mamf.franco@gmail.com. Orcid: <https://orcid.org/00000002-0159-4109>. Agencia de Fomento: FAPEMIG.

${ }^{(* *)}$ Pedagoga. Professora auxiliar da Educação Especial em Ouro Preto/MG. Integrante do projeto de pesquisa Ações extensionistas e pesquisa-ação em contextos de inclusão: impactos na formação docente inicial e continuada na região dos Inconfidentes. E-mail: crisdiasr1@hotmail.com. Orcid: 〈https://orcid.org/0000-0003-2923-6909>.

${ }^{(* * *)}$ Formada em Pedagogia pela Universidade Federal de Ouro Preto. Integrante do projeto de pesquisa Ações extensionistas e pesquisa-ação em contextos de inclusão: impactos na formação docente inicial e continuada na região dos Inconfidentes. Email: fabiananascimento2011@bol.com.br. ORCID: https://orcid.org/0000-0002-1394-6378.
} 
devem oferecer cursos de especialização para a área da inclusão, bem como ofertar, no currículo dos cursos de licenciatura, disciplinas que discutam as práticas inclusivas, o processo de desenvolvimento da criança e possíveis recursos e métodos de ensino para alunos com deficiência, considerando que com uma base teórica consistente, o professor poderá ter uma melhor capacidade para refletir e construir uma prática mais inclusiva. (BRASIL, 2001).

A pesquisa aqui apresentada buscou investigar, a partir de um recorte do tema inclusão da pessoa com deficiência no sistema regular de ensino, as percepções e aspectos da formação do professor na atuação com alunos com deficiência nas salas de recursos multifuncionais de instituições públicas no município de Ouro Preto/Minas Gerais. A pesquisa está vinculada a um projeto mais amplo de pesquisa intitulado: "Práticas pedagógicas de alfabetização, leitura e escrita em contextos de inclusão" desenvolvido por pesquisadores da Universidade Federal de Ouro Preto, que recebeu financiamento do CNPq. A investigação se deu por meio da abordagem qualitativa, que utilizou como instrumento entrevistas semiestruturadas com as professoras que atuam no AEE.

\section{FORMAÇÃO DE PROFESSORES PARA A EDUCAÇÃO INCLUSIVA/ESPECIAL}

No contexto atual brasileiro é possível perceber que com as novas demandas no ambiente escolar torna-se necessário que o Currículo, para a formação de professores, possa estar atualizado e em consonância com essas novas demandas com o objetivo de se realizar uma formação que os capacite ao processo de ensino-aprendizagem que tenha como base a diferença e a inclusão. Sabemos que há uma orientação política para que a formação de professores atenda às diversidades, seja no que tange o trabalho com alunos com deficiência, transtornos, necessidades educacionais especiais, questões étnico-raciais, indígenas ou outras perspectivas da diferença. Porém, o desenvolvimento formativo dos profissionais da educação depende das políticas públicas de formação docente que o Estado e/ou o Munícipio, no qual ele está inserido, oferecem e das condições que esses professores possuem para realizar essa formação. Entretanto, o que não pode deixar de acontecer é que cada professor garanta em sala de aula uma prática pedagógica que seja capaz de lidar com as diferenças e diversidades no sentido de inclusão de todos os alunos considerando suas especificidades (JESUS e EFFGEN, 2012).

Os cursos de formação de professores costumam abordar a Educação Inclusiva em uma perspectiva mais teórica com pouco aprofundamento ou reflexão sobre as práticas pedagógicas em sala de aula (GATTI, 2010). Isso pode ser reflexo do modelo de formação que se tem. Embora ao longo da história tenhamos vários avanços, os modelos tecnicistas e conteúdistas ainda são muito presentes. uNas licenciaturas, Gatti (2010) nos mostra que a formação de professores não pode ser 
pensada apenas na perspectiva conteudista, mas também em uma perspectiva social que agregue valores à comunidade escolar. Assim:

A formação de professores profissionais para a educação básica tem que partir de seu campo de prática e agregar a este os conhecimentos necessários selecionados como valorosos, em seus fundamentos e com as mediações didáticas necessárias, sobretudo por se tratar de formação para o trabalho educacional com crianças e adolescentes (GATTI, 2010, p.1375).

Nesse sentido, quando os professores se deparam com alunos com deficiência se veem despreparados, e acreditam que precisam ter um conhecimento amplo sobre a deficiência, principalmente sobre a patologia reforçando assim, a perspectiva médica que se faz muito presente no imaginário social. Porém, o que eles precisam é conhecer o aluno como sujeito social, cultural e entender de práticas pedagógicas que auxiliarão no seu processo de aprendizagem (RODRIGUES, 2006).

Nesse sentido, na formação inicial dos professores da educação básica há uma tensão na relação teoria e prática, produzindo discursos segregadores, e práticas pedagógicas pouco aprofundadas nos cursos de licenciatura (GLAT, 2006). A fim de mudar essas condutas excludentes em sala de aula, seria importante que o professor buscasse aperfeiçoar sua formação inicial com um olhar voltado para a Educação Inclusiva. Por outro lado é de fundamental importância que as instituições de ensino desenvolvam um modelo de formação que dê conta de atender às demandas sociais. Saberes como desenvolvimento humano, conhecimento sobre os tipos de deficiências, especificidades no trabalho pedagógico, o apoio de recursos pedagógicos e processo avaliativo adequado às necessidades de cada aluno, podem contribuir para a construção de metodologias e estratégias pedagógicas menos excludentes (RODRIGUES, 2006).

Nesse contexto, é importante ressaltar que as leis e políticas públicas desenvolvidas no Brasil apontam para novas abordagens em relação à formação de professores. Dentre elas podemos destacar a Lei de Diretrizes e Bases (LDB/96), Diretrizes Nacionais para a Educação Especial na Educação Básica (2001), Diretrizes Curriculares Nacionais para os cursos de graduação em Pedagogia (2006) e a Política Nacional de Educação Especial na Perspectiva da Educação Inclusiva (2008).

A LDB de 1996 foi uma das ações políticas que além de reorganizar os níveis de ensino da educação, propôs abordar a formação de professores discutindo desde as instituições especializadas para a formação profissional até os saberes necessários para a docência. Nesse documento a formação docente para a Educação Inclusiva é discutida de forma restrita destacando apenas o perfil 
de dois tipos de professores para o atendimento dos alunos com necessidades educacionais especiais. Um com formação especializada para o atendimento individual e outro capacitado para integrar os alunos nas salas de aula regular. É possível perceber que a LDB/96 não especifica qual a formação ideal para atuar na educação em uma perspectiva inclusiva no ensino regular (ALMEIDA, 2004).

Após a LDB/96 outra política importante para a formação de professores instituída em 2001 foram as Diretrizes Nacionais para a Educação Especial na Educação Básica, que ressaltam a importância da formação docente para atuar na educação inclusiva. Esse documento trata da diferença da formação de professores capacitados e professores especializados. Os professores capacitados devem possuir formação inicial em nível médio ou superior que abarque a educação especial/inclusiva. Já os professores especializados além da formação inicial, devem possuir cursos de especialização ou pós-graduação na área da educação especial/inclusiva. Baseadas nas diretrizes foram introduzidas em 2002 no currículo de formação de professores disciplinas especificas da área da inclusão através das Diretrizes Curriculares para a Formação de Professores da Educação Básica, em nível superior, curso de licenciatura de graduação plena (BRIDI, 2011).

A Política Nacional de Educação Especial na Perspectiva da Educação Inclusiva (2008) foi de suma relevância para a concretização da educação inclusiva no cenário nacional promovendo avanços para a educação especial desde a acessibilidade até a exigência na qualificação dos professores que atuam na área propondo que:

Para atuar na educação especial, o professor deve ter como base da sua formação, inicial e continuada, conhecimentos gerais para o exercício da docência e conhecimentos específicos da área. Essa formação possibilita a sua atuação no atendimento educacional especializado, aprofunda o caráter interativo e interdisciplinar da atuação nas salas comuns do ensino regular, nas salas de recursos, nos centros de atendimento educacional especializado, nos núcleos de acessibilidade das instituições de educação superior, nas classes hospitalares e nos ambientes domiciliares, para a oferta dos serviços e recursos de educação especial (BRASIL, 2008, p.11).

Diante do contexto atual, as políticas públicas direcionadas para a formação de professores resultaram em avanços na inclusão educacional, porém é necessário maiores investimentos na formação continuada tanto por parte dos professores quanto das redes de ensino em ofertarem cursos de capacitação e especialização aos docentes que atuam na educação básica, a fim de 
transformar as suas práticas pedagógicas em sala de aula promovendo o ensino na perspectiva da educação inclusiva.

\section{FORMAÇÃO DE PROFESSORES PARA O ATENDIMENTO EDUCACIONAL ESPECIALIZADO}

No início da década de 1970, a formação de professores para a Educação Especial passou a ser em nível superior, na qual a reformulação do curso de Pedagogia habilitava as especializações para o ensino especial. Com a promulgação da LDB/96, percebeu-se que para atender as demandas da inclusão escolar das crianças com deficiência, eram necessários professores generalistas, capacitados para atuar no ensino regular de sala de aula e professores especialistas com conhecimentos e práticas mais aprofundados sobre a deficiência e capacitação em nível superior na área da Educação Especial. Em 2008 a Política Nacional de Educação Especial na Perspectiva da Educação Inclusiva foi uma das pioneiras a ressaltar o atendimento educacional especializado e a formação de professores e profissionais da educação para a inclusão (ROSALEN; BORTOLOZZI, 2011).

No contexto da Educação Especial, fundamentado na Política Nacional de Educação Especial na Perspectiva da Educação Inclusiva (2008) foram estabelecidas as Salas de Recursos multifundionais (SRM). Um programa de âmbito nacional, que tem como objetivo atender aos alunos da Educação Especial no Atendimento Educacional Especializado no sistema regular de ensino. O AEE por sua vez consiste em uma rede de serviços especializados aos alunos com deficiência que perpassa todos os níveis e modalidades da educação que tem como principal função complementar o ensino desses alunos (PERTILE; ROSSETTO, 2015).

Com o avanço das políticas públicas educacionais voltadas para a Educação Inclusiva surgem novas propostas direcionadas ao Atendimento Educacional Especializado as quais tratam da formação de professores para atuar na educação especial no ensino regular. Uma das primeiras ações regulamentadas foram as Diretrizes Operacionais da Educação Especial para o Atendimento Educacional Especializado na Educação Básica (BRASIL, 2009) que considera que os recursos de acessibilidade aos alunos com deficiência, devem assegurar condições de acesso ao currículo, a utilização de materiais didáticos e pedagógicos, aos sistemas de comunicação e informação, ao transporte e mobiliários adequados. Além disso, dispõe que para atuação no AEE é necessário formação inicial em Licenciatura e formação especializada na área da Educação Especial (BRASIL, 2009). Porém, não há um curso especifico para que o professor atue nas salas de recursos, pois, essa formação, na maioria das vezes, se dá em serviço e na modalidade à distância, permitindo à 
acessibilidade a capacitação desses professores que já atuam e têm um tempo mais restrito. Contudo, esses cursos oferecidos na modalidade EAD por serem ofertados em curto período de tempo podem não qualificar a formação profissional para o Atendimento Educacional Especializado, pois não abrangem, de forma profunda, os conhecimentos necessários para subsidiar a atuação e as funções do professor nas salas de recursos (ROSSETTO, 2015).

Em relação às funções do professor de AEE, as Diretrizes Operacionais da Educação Especial para o Atendimento Educacional Especializado na Educação Básica (BRASIL, 2009) destacam que ele deve ser capaz de :

a. Identificar, elaborar, produzir e organizar serviços, recursos pedagógicos, de acessibilidade e estratégias considerando as necessidades específicas dos alunos público-alvo da educação especial;

b. Elaborar e executar plano de atendimento educacional especializado, avaliando a funcionalidade e a aplicabilidade dos recursos pedagógicos e de acessibilidade;

c. Organizar o tipo e o número de atendimentos aos alunos na sala de recursos multifuncional;

d. Acompanhar a funcionalidade e a aplicabilidade dos recursos pedagógicos e de acessibilidade na sala de aula comum do ensino regular, bem como em outros ambientes da escola;

e. Estabelecer parcerias com as áreas intersetoriais na elaboração de estratégias e na disponibilização de recursos de acessibilidade;

f. Orientar professores e famílias sobre os recursos pedagógicos e de acessibilidade utilizados pelo aluno;

g. Ensinar e usar recursos de Tecnologia Assistiva, tais como: as tecnologias da informação e comunicação, a comunicação alternativa e aumentativa, a informática acessível, o soroban, os recursos ópticos e não ópticos, os softwares específicos, os códigos e linguagens, as atividades de orientação e mobilidade entre outros; de forma a ampliar habilidades funcionais dos alunos, promovendo autonomia, atividade e participação.

h. Estabelecer articulação com os professores da sala de aula comum, visando a disponibilização dos serviços, dos recursos pedagógicos e de acessibilidade e das estratégias que promovem a participação dos alunos nas atividades escolares.

i. Promover atividades e espaços de participação da família e a interface com os serviços setoriais da saúde, da assistência social, entre outros. 
Após mencionar as funções atribuídas ao professor do AEE é possível compreender que seu trabalho pedagógico envolve várias ações, o que o torna um profissional multifuncional. É necessário considerar que o grupo de crianças com o qual ele trabalha é diversificado, sendo que cada um possui suas especificidades. Além disso, ele pode ser visto como o profissional responsável por promover a inclusão dos alunos com deficiência na escola. Porém, as práticas desenvolvidas nas salas de Atendimento Educacional Especializado devem se articular com o trabalho realizado na sala de aula regular, visto que o AEE é uma complementação desse trabalho pedagógico (ROSSETTO, 2015).

Antes da implementação das políticas educacionais voltadas para o Atendimento Educacional Especializado, a escolarização das pessoas com deficiência era ofertada em instituições assistencialistas. Só em 2011 o Atendimento Educacional Especializado passa a ter status de lei, na qual dispõe de todos os fazeres necessários para a implementação das salas de recursos nas instituições públicas de ensino. Esta tendo como função complementar a formação dos alunos, identificando, elaborando e organizando recursos pedagógicos, promovendo acessibilidade e participação das pessoas com necessidades educacionais especiais (ROSALEN e BORTOLOZZI, 2011).

Diante do exposto percebemos que as políticas públicas para a Educação Inclusiva referemse à formação de professores de forma restrita, não especificando os cursos especializados para atuação desses profissionais no Atendimento Educacional Especializado. Vimos que se exige, do professor, um amplo conhecimento para exercer suas funções nas salas de recursos e reflexão sobre suas práticas que têm que se adequar às especificidades de cada aluno da Educação Especial. Esse profissional, acaba por ter que se ver com uma multiplicidade de situações e contextos que irão exigir uma super atuação.

\section{METODOLOGIA}

Utilizamos a abordagem qualitativa por se tratar de uma perspectiva metodológica, na qual o pesquisador tem contato direto com o ambiente a ser investigado na pesquisa. A abordagem qualitativa [...] "envolve a obtenção de dados descritivos, obtidos no contato direto do pesquisador com a situação estudada, enfatiza mais o processo do que o produto e se preocupa em retratar a perspectiva dos participantes" (BOGDAN; BIKLEN, 1982 apud LUDKE; ANDRÉ, 1986, p.13).

Para identificar o que pensam as professoras utilizamos como instrumento de coleta de dados a entrevista-semiestrutura. De acordo com Duarte (2004) para se utilizar da entrevista, o 
pesquisador deve desde o início analisar o contexto externo, as influências locais, sociais, culturais em que os sujeitos a serem pesquisados estão inseridos. Nesse sentido, a análise dos dados coletados a partir da entrevista buscam refletir esses princípios.

\section{CONTEXTO DA PESQUISA}

A pesquisa foi realizada no município de Ouro Preto região central de Minas Gerais, na qual existem apenas duas salas de recursos multifuncionais ligadas à rede municipal de ensino. Situadas em bairros distantes um do outro. Essas salas atendem às demandas de alunos com deficiência e necessidades educacionais específicas, geralmente das escolas municipais da comunidade onde está localizada.

Cada sala de recurso dispõe de uma profissional da educação com capacitação para área da Educação Especial que atende os alunos público-alvo dessa modalidade de ensino no contra turno do horário de aula regular. As salas de recursos multifuncionais contam com diversos materiais tais como, computadores, jogos pedagógicos, livros em Braile, materiais adaptáveis, entre outros, que servem de apoio para o atendimento educacional especializado.

\section{OS SUJEITOS DA PESQUISA}

Participam da pesquisa duas professoras de salas multifuncionais. Para nomear as duas professoras entrevistadas e como forma de garantir o anonimato chamamos a primeira de professora P1 e a segunda de professora P2. A professora P1 possui formação em Magistério Superior com especialização em Educação Inclusiva, tem dezesseis anos de carreira docente, sendo seis de atuação no AEE. Já a professora P2 também possui Magistério Superior, mas não tem PósGraduação na área da Educação Especial, fez alguns cursos oferecidos pela Universidade Federal de Ouro Preto e pela Secretária de Educação, que a permitiu atuar no Atendimento Educacional Especializado.

\section{FORMAÇÃO DOCENTE PARA EDUCAÇÃO ESPECIAL NA PERSPECTIVA DA EDUCAÇÃO INCLUSIVA: ALGUMAS REFLEXÕES DAS PROFESSORAS}

Nesse tópico, abordaremos a percepção que as professoras possuem sobre os processos de formação e sobre os conhecimentos e habilidades necessárias para atuar no Atendimento Educacional Especializado. Inicialmente é importante ressaltar que com base na literatura que fundamenta o estudo, no que tange à formação de professores, percebemos que nos currículos dos 
cursos de licenciatura a educação inclusiva não é um tema muito abordado, sendo que isso se reflete nas práticas que, por vezes, costumam ser superficiais (GATTI, 2010).

Considerando essa perspectiva, o primeiro questionamento que fizemos às professoras foi como percebem a formação inicial para a atuação no campo da educação especial na perspectiva da educação inclusiva e se ela, de alguma maneira, se mostra consistente para o exercício da profissão. As duas afirmam que:

P1: Não é não, infelizmente. A formação inicial é apenas um passo, porque o resto tem correr atrás mesmo. Fazer cursos, conversar com as mães de crianças deficientes, estar indo na, APAE, porque trabalhar com criança especial envolve muito o lado profissional. Tem que ter um auto controle muito grande, tem que saber separar bem o lado emotivo, profissional, tem que estar bem separado senão não consegue não.

P2: Não, claro que não [...] A única coisa que eu tive foi Psicologia, mas não abordou a Educação Inclusiva, até mesmo porque nessa época não estava na moda, como se diz. Hoje em dia está mais falado, os familiares estão cobrando mais e com essa cobrança a escola tem que fazer alguma coisa.

Nas falas das professoras é possível observar que elas concordam que a formação inicial não é suficiente para atuar na educação especial, principalmente na perspectiva inclusiva. Esse entendimento pode ser explicado pelo fato de que no período em que se formaram a inclusão não era um tema tão discutido como é atualmente, o que se reflete na sua ausência como componente curricular. Entretanto, nas suas falas é possível inferir que elas têm clareza de que o professor precisa estar em constante aperfeiçoamento. Nesse sentido, compreendemos que somente a formação inicial não fornece subsídios para o professor atuar com alunos público-alvo da educação especial, pois não contempla as demandas e diversidades do tema, sendo necessária a complementação em cursos de pós-graduação. Fica claro que há a necessidade de se pensar a formação docente no campo da educação especial e inclusiva. Como podemos pensar a entrada da criança com deficiência em um ambiente com pessoas que não sabem lidar com esse sujeito? Alves (2012) nos diz que apenas a graduação não é suficiente para que o profissional docente atue no seu campo de trabalho, é necessário que ele esteja em constante atualização de seus conhecimentos e práticas de acordo com as demandas do contexto escolar.

Por outro lado, entendemos que o professor não pode ser o único responsável pelo processo educacional desses sujeitos. É necessário que as políticas públicas de fato sejam implementadas, que saiam do papel e passem a ocupar um lugar de destaque no cenário educacional. É necessário 
também, que as escolas se organizem para receber esse público e que os profissionais dessa instituição sejam sensibilizados e formados para lidar com as diferenças.

Outro aspecto importante a ser considerado no processo de inclusão e da educação especial é o Atendimento Educacional Especializado. Embora seja uma política pública definida em lei (BRASIL, 2011), o que se tem visto é que a sua implementação caminha a passos lentos.

De acordo com as Diretrizes Operacionais da Educação Especial para o Atendimento Educacional Especializado na Educação Básica (BRASIL, 2009) o AEE corresponde a uma atividade educacional complementar a sala de aula regular que tem por função diminuir as barreiras dos alunos com deficiências e necessidades especiais. Nesse sentido, abordamos o conceito que as professoras têm sobre o Atendimento Educacional Especializado, na qual elas afirmam que:

P1: "Não é uma aula de recuperação nem aula de reforço. Geralmente a gente busca trabalhar aspectos cognitivos, afetivos, porque tem criança que tem déficit de aprendizagem, mas não tem deficiência nenhuma, porque agora a gente tem que atender, pois antes recebia essas crianças só com laudo, agora saiu uma lei que a gente tem que atender. Se a escola detectou que aquela criança tem dificuldade de aprendizagem, demora muito para aprender, significa que ele precisa de outros recursos, então a gente trabalha com estes recursos, estimulando. Por exemplo, com joguinhos, algo que para o professor fazer em sala de aula é mais complicado. Então a gente trabalha os aspectos afetivos, cognitivos, linguagem, percepção oral, motricidade, raciocínio lógico, socialização, atenção, concentração, autoestima, autoconfiança e oralidade".

P2: [...]"a concepção agora voltada para sala de recurso, você tem que acreditar, entrar no mundo da criança, você tem que ter a sensibilidade para perceber o que aquela criança precisa naquele momento, as vezes trabalhar de forma diferente um conteúdo que ele não está aprendendo não é suficiente, acho que tem que garantir a confiança dele em você para que possa fazer um trabalho com ele. Acho que as pessoas estão precisando ser mais escutadas e essas crianças também, elas são tão reprimidas, que as vezes se você para e escuta o que ela tem a dizer, vai questionando, tentando envolver aquele assunto em determinado objetivo que se tem com ele, ai você consegue".

$\mathrm{Na}$ fala da professora P1 é possível notar que ela tem certa clareza em relação as funções do professor no atendimento educacional especializado, considerando o que apontam as políticas públicas para a Educação Especial. Nelas se, enfatiza que o professor tem várias atribuições, como por exemplo: identificar as demandas dos alunos; criar e aplicar recursos pedagógicos que auxiliem no processo de ensino e aprendizagem; usar diferentes estratégias pedagógicas conforme as 
especificidades dos sujeitos, entre outros. Dado isso, ressaltamos a importância do atendimento educacional especializado, pois visa atender o aluno de forma individualizada complementando o ensino de sala de aula de acordo com suas necessidades educacionais, utilizando de recursos e estratégias pedagógicas que, muitas vezes, não estão acessíveis e executáveis no trabalho em sala de aula regular.

Ao contrário de P1, é possível identificar que a professora P2, evidência compreender o atendimento educacional especializado de outra forma. Quando ela relata que "as vezes trabalhar de forma diferente um conteúdo que ele não está aprendendo não é suficiente". Ela nos aponta para uma perspectiva que não é exatamente aquela preconizada pelo AEE. Conforme os documentos oficiais o AEE não deve ser o espaço de reforço de conteúdos trabalhados em sala de aula. Ele deve ser o espaço para atendimento especial, ou seja, um atendimento que responda as necessidades dos sujeitos que dele participam. Esses atendimentos devem priorizar o desenvolvimento das habilidades que esses sujeitos possuem como forma de favorecer a sua aprendizagem, o seu desenvolvimento, a sua participação social, entre outros. Contudo, é preciso ressaltar que essa professora se preocupa em ter um diálogo com o aluno para perceber as dificuldades e problemas pelos quais está passando. É importante lembrar que ela diz da relevância de se escutar esse sujeito, ouvir o que ele tem a dizer. Esse é um elemento fundamental no processo do atendimento especializado e no processo de ensino e aprendizagem. É preciso que esse sujeito tenha voz e possa dizer das suas especificidades. Em relação à afetividade no processo de ensino, essa se faz necessária, pois de acordo com Muller (2002), ela é essencial na aprendizagem do aluno, porque dessa maneira poderá haver uma melhor interação com o professor e, por conseguinte, em construções mais inclusivas no ambiente escolar.

Acerca das concepções que as professoras têm sobre o Atendimento Educacional Especializado investigamos, também, o que consideram relevante na formação docente para atuar no AEE como podemos verificar nas falas a seguir:

P1: "Eu acho que enquanto professores temos que estar buscando, então é interessante você ter ou uma graduação ou uma pós-graduação na área da deficiência, porque não tem como o professor do AEE saber tudo não, mas se ele tiver uma formação básica inicial mais para a frente ele poderá estar se especializando em alguma área. Mas assim, tem que ter uma formação, cursos básicos, o interessante também é procurar pequenos cursos de capacitação porque ai você aprende mais a lidar com as crianças, você aprende a entender, porque não adianta ter apenas o diploma bonitinho ali e não ter a prática não. E os cursos de capacitação geralmente eles oferecem mais a prática do que o nosso curso mesmo de formação. Porque na formação você tem que fazer 
aquelas cadeiras especificas, você aprende, mas de forma que não é aprofundado, você aprende aquela parte acadêmica. Agora você fazendo estes cursos de capacitação convive mais e troca mais experiências".

P2: Olha, acho que para a educação no geral, a partir do momento que a sociedade aceita o indivíduo como ele é e abarca que somos todos diferentes mesmo, então já é um passo para você querer e estudar [...] para ter conhecimento, embasamento para fazer alguma coisa, porque fazer na suposição às vezes você acerta, mas não é sempre [...] Agora, quanto aos outros professores os cursos são oferecidos, mas não querem fazer, ás vezes por resistência, às vezes por tempo, cada um tem seu motivo, o salário que não te permite disponibilizar tempo para poder ir, mas que todos deveriam estudar deveria. A secretaria podia montar cursos dentro dos horários em cima dos dias escolares.

Com base nas falas das professoras é possível perceber que elas entendem de que apenas a formação inicial é insuficiente para atuar nas salas de recursos. Nota-se que a professora P1 afirma que a formação para a educação inclusiva deve estar em constante aprimoramento, pois somente a formação inicial não fornece suporte para atuação nesse campo. É necessário que o professor busque cursos de capacitação para ampliar os conhecimentos sobre a prática com alunos com necessidades educacionais especiais. Como é proposto nas Diretrizes Operacionais da Educação Especial para o Atendimento Educacional Especializado na Educação Básica (BRASIL, 2009), para atuar no AEE é necessário além da formação inicial em licenciatura, cursos de especialização na área da Educação Especial. Essa definição do documento oficial nos remete à necessidade de se pensar o modelo de formação inicial que temos, bem como, o modelo de desenvolvimento e qualificação profissional continuada. Como promover uma formação adequada e que qualifique os professores no exercício de sua profissão? Para Gatti e Barreto (2009) a formação de professores deve ser pensada de acordo com as demandas recorrentes no contexto educacional. Sendo assim, a formação do docente deve partir do seu campo de atuação, aprimorando suas metodologias de trabalho, necessárias a aquele determinado momento de ensino e aprendizagem com os alunos.

Já a professora P2 acredita que para atuar na área da Educação Especial o professor primeiramente deve compreender as diferenças e ter um embasamento teórico para desenvolver a sua prática nas salas de recursos. Ressalta também a importância de cursos oferecidos pela secretaria de ensino em horários flexíveis ao trabalho do professor. Diante disso, observamos que a P2 compreende que o professor precisa estar em constante capacitação, porém, é necessário que o sistema de ensino adeque a jornada de trabalho possibilitando a formação continuada do professor. Nessa perspectiva Mendes e Romanowski (2006), afirmam que os programas de formação 
continuada devem levar em conta alguns fatores como, as condições de trabalho dos professores, a organização e o funcionamento das escolas, pois dessa maneira o professor conseguirá se desenvolver profissionalmente.

Podemos aqui ir um pouco mais além. Observamos na fala de P2 vários elementos importantes a serem considerados. A professora aponta para a necessidade da formação para a atuação, para políticas públicas de formação e para uma organização estrutural que qualifique o exercício da docência e dê ao professor condições de se desenvolver profissionalmente. Nesse sentido, nos perguntamos: como fazer inclusão em condições tão adversas e muitas vezes precárias? A fala da professora nos leva a refletir sobre o modelo que temos hoje e suas precariedades. Tornasse quase impossível desenvolver um trabalho de qualidade nas condições em que a docência se dá. Para Aleixo (2014) a qualificação do professor deve ser vista como primordial, pois pertence a uma etapa de reconstrução de suas práticas e de sua carreira profissional, buscando aprimorar sua práxis docente no contexto escolar e afirmar sua identidade profissional.

Se de uma forma geral a formação docente precisa ser rediscutida, repensada e revista, isso não é muito diferente quando localizamos essa perspectiva em ambientes específicos. No caso da rede municipal de Ouro Preto a história se repete e se mantêm. Nas falas abaixo as professoras apontam para a escassez de políticas de formação desenvolvidas no município:

P1: “As políticas de formação continuada que o município oferece aqui tem a parceria com o Estado, com outros municípios e com o IFMG e a UFOP. Quando a gente recorre a estas instituições eles sempre ajudam. Tem o apoio da Universidade. Acho que a gente tem até que procurar mais, pois lá tem a sala da NEI, o pessoal de lá são muito abertos [...] O certo seria de dois em dois meses, mas é feito de 3 a 4 meses, durante o ano. Não são muitos cursos que tem não. E geralmente esse ano que passou a grande parte dos cursos foi ofertado pela prefeitura de Mariana. Mariana está um passo à frente, Ouro Preto é mais garrado".

P2: "A Universidade tem vínculo com a Secretaria de Educação e como tem os trabalhos de pesquisa eles oferecem, tem o NEI, o núcleo de Inclusão, então eles recebem para oferecer cursos. Então tem essa parceria, mas infelizmente o número de vagas é limitado, nem todos participam, às vezes tem boicote, além disso, tudo, às vezes a demanda é muito maior que a quantidade de vagas oferecidas. A prefeitura de Mariana deu um show, eu fiz inúmeros cursos pela prefeitura de Mariana. O pessoal da sala de recursos de lá tem Libras, Braile, Deficiência Intelectual, tudo, é um espetáculo". 
Identificamos nas falas das professoras em relação à formação continuada, que a rede municipal de Ouro Preto não tem investido na capacitação de professores que atuam na educação especial ou, se o faz, é de forma bastante restrita. Os cursos dos quais participaram foram geralmente oferecidos pela Universidade Federal de Ouro Preto, pelo Estado de Minas Gerais ou mesmo pela prefeitura da cidade vizinha. Essa revelação nos mostra que as professoras têm exercido a função de professores do AEE sem uma formação adequada. Conforme o documento oficial (BRASIL, 2009) o professor de AEE deve possuir especialização na área da Educação Especial. Ao analisarmos tal fato podemos perceber que as políticas públicas nacionais preconizadas em relação ao processo de inclusão e de formação de professores nem sempre encontram repercussão nos espaços fins. Queremos com isso dizer que, por mais que o governo federal tenha investido em projetos e políticas no campo da inclusão, nem sempre elas se materializam nas ações dos munícipios e estados. Nem sempre os governos locais investem na concretização de tais políticas nacionais. Aqui temos o exemplo claro de comparação entre municípios vizinhos. As professoras revelam que realizaram formação em cursos oferecidos por outra prefeitura. Além disso, temos uma universidade e o Estado como instituições que acabam por fazer aquilo que o município se omite em fazer.

É importante ressaltar o esforço das docentes em buscar uma formação que as possibilite qualificar a atuação. Por mais que o município não atenda as necessidades e demandas dos seus servidores, eles têm feito o esforço em buscar formas de se qualificarem para atuar diante da realidade que lhes é colocada. Sem uma política clara do município é possível pensar que os professores acabam por buscar formação sem uma orientação adequada. Temos aqui então questões importantes a serem pensadas: "que tipo de formação os professores buscam por conta própria?" "se o poder público se omite na execução de políticas públicas para a inclusão, o que cabe aos professores fazer?”. Segundo Gatti e Barreto (2009) é papel do poder público garantir a formação inicial e continuada de professores, porém os modelos de formação docente precisam ser revistos, visto que as legislações e políticas públicas não consideram as diferenças existentes nas condições de trabalho, carreira e salários dos professores. Sendo assim, são necessárias políticas que valorizem a profissão docente para estimular os professores a se capacitarem.

\section{CONSIDERAÇÕES FINAIS}

A investigação nos permitiu constatar que a demanda de alunos público-alvo da educação especial está crescendo na rede municipal de ensino e que o número de salas de recursos multifuncionais do município ainda são insuficientes em relação a demanda de alunos. Em Ouro 
Preto existem apenas duas salas de recursos na rede municipal de ensino que contam com o trabalho de duas professoras capacitadas para atuarem na educação especial. Se pensarmos um município com cerca de 70 mil habitantes, esse número se torna insignificante. Nesse sentido, o estudo nos possibilitou identificar o baixo investimento público na constituição daquilo que é de direito do cidadão e dever do Estado. O movimento de inclusão não é recente e pelo o que observamos Ouro Preto caminha a passos muito lentos para a sua concretização como política pública do município. Isso nos remete a discussões que fizemos ao longo do estudo sobre a precarização da educação e, particularmente, sobre o lugar que a educação especial ocupa nas políticas públicas do município.

Se por um lado o investimento público na formação do professor é mínimo, por outro esse sujeito busca a construção de sua identidade como professor de AEE de forma solitária. Podemos dizer que, com muito esforço, esse professor se faz profissional nesse campo tecendo remendos na sua formação. Nem sempre essa formação é orientada. Muitas vezes ela se faz pelas necessidades e demandas que emergem a partir do contexto da prática. Por um lado isso é significativo, pois temos a prática movimentando a constituição de saberes que permitam a reflexão mais qualificada sobre ela. Por outro, fica a sensação de que as ações no campo da formação docente são de responsabilidade dos próprios professores. Temos clareza de que esse professor deve ser o gestor de sua formação, porém, não pode ser o único responsável. Cabe ao poder público evidenciar esforços para que ele se qualifique e, por conseguinte, a educação pública seja beneficiada. Temos a percepção de que as ações no campo da formação docente se dão sempre a posteriori. Por mais que as políticas públicas apontem para as necessidades, é preciso que, primeiro, essas necessidades emerjam, se consolidem para então, se iniciar um processo que alcance essas demandas que já se concretizaram e estão em processo de transformação. Ou seja, o Estado está sempre a largos passos atrás. 


\section{REFERÊNCIAS}

ALEIXO, José Carlos C. Professores do $1^{\mathbf{0}}$ seguimento do Ensino Fundamental da cidade de Nova Iguaçu: aproximações entre qualificação e identidade. 237 f. Dissertação (Mestrado em Educação) - Instituto de Educação e Instituto Multidisciplinar, Universidade Federal Rural do Rio de Janeiro, Rio de Janeiro, 2014.

ALMEIDA, Maria Amelia. Formação do professor para a Educação Especial: história, legislação e competências. Revista do Centro de Educação, n. 24, 2004.

ALVES, Ivelise Kraide. A formação docente no Contexto da Educação Inclusiva. 70f. Trabalho de conclusão de curso de especialização (Especialização em Educação Especial e Processos Inclusivos) - Faculdade de Educação, Universidade Federal do Estado do Rio Grande do Sul, Porto Alegre, 2012.

BRASIL. Ministério da Educação. Diretrizes nacionais para a educação especial na educação básica. Secretaria de Educação Es pecial-MEC; SEESP, 2001.

Ministério da Educação. Política Nacional de Educação Especial na perspectiva da Educação Inclusiva. Secretária de Educação Especial-MEC; SEESP, 2008.

Ministério da Educação. Resolução 04, de 2 de outubro de 2009. Institui Diretrizes Operacionais para o Atendimento Educacional Especializado na Educação Básica, modalidade Educação Especial. Brasília: MEC/CNE/CEB, 2009.

Ministério da Educação. Lei 7.611, de 17 de novembro de 2011. Dispõe sobre o Atend imento Educacional Especializado-AEE. Brasília: MEC, 2011.

BRIDI, Fabiane Romano S. Formação Continuada em Educação Especial: O Atendimento Educacional Especializado. UNISUL，Tubarão, SC, v. 4, n. 7, p. 187-199, 2011.

DUARTE, Rosália. Entrevistas em pesquisas qualitativas. Educar, Curitiba, n. 24, p. 213-225, 2004.

GATTI, Bernadete A.; BARRETO, Elba Siqueira S. Professores do Brasil: impasses e desafios. Brasília: UNESCO, 2009, 294. p.

Formação de professores no Brasil: características e problemas. Educ. Soc., Campinas, v. 31, n. 113, p. 13551379, out./dez. 2010.

GLAT, Rosana. Formação de professores na educação inclusiva: diretrizes políticas e resultados de pesquisas. Pernambuco: [s.n.], 2006.

JESUS, Denise Meireles; EFFGEN, Ariadna Pereira S. Formação docente e práticas pedagógicas: conexões, possibilidades e tensões. In: MIRANDA, T.G; FILHO, T.A.G. (Orgs.). O professor e a educação inclusiva: formação, práticas e lugares. Salvador: EDUFBA, 2012. p. 17-25.

LUDKE, Menga; ANDRÉ, Marli E. D. A. Pesquisa em educação: Abordagens qualitativas. São Paulo: EPU, 1986.

MENDES, Katia V. Mosconi; ROMANOWSKI, Joana Paulin. Formação Continuada de professores: os modelos com base na racionalidade técnica. Educere, Paraná, 2006.

MULLER, Luiza de Souza. A interação professor-aluno no processo educativo. Integração, ano VIII, n. 31, nov. 2002.

PERTILE, Eliane Brunetto; ROSSETTO, Elisabeth. Trabalho e formação docente para o atendimento educacional especializado. Revista Ibero-America de Estudos em Educação, v. 10, p. 1186-1198, 2015.

RODRIGUES, David. Dez ideias (mal) feitas sobre a Educação Inclusiva. In: RODRIGUES, David. (Org.). Inclusão e Educação: doze olhares sobre a Educação Inclusiva. São Paulo: Summus Editorial, 2006.

ROSALEN, Patrícia Cristina; BORTOLOZZI, Kyrlian. Formação de professores para o Atendimento Educacional Especializado (AEE). São Paulo: [s.n.], 2011.

ROSSETTO, Elisabeth. Formação do professor do Atendimento Educacional Especializado: a Educação Especial em questão. Revista Educação Especial, v. 28, n. 51, p. 103-116, 2015. 


\section{RESUMO}

O desafio colocado para a atuação do professor no atendimento educacional especializado (AEE) nos levou a investigar o que pensam professores de AEE acerca da formação docente, particularmente, a formação para atuar no AEE. Trata-se de um estudo de caso desenvolvido com professores de salas multifuncionais (AEE) de escolas públicas do município de Ouro Preto. O Estudo evidencia que embora existam politicas nacionais para a inclusão em educação, nem sempre os municípios desenvolvem essas políticas a contento. Revela que o investimento público na formação do professor tem sido mínimo obrigando o sujeito professor a buscar a sua formação de forma individual e solitária. Podemos dizer que, com muito esforço, esse professor se faz profissional, nesse campo, tecendo remendos na sua formação.

Palavras-chave: Inclusão em Educação. Atendimento Educacional Especializado. Formação docente.

\section{ATENCIÓN EDUCACIONAL ESPECIALIZADA: QUÉ PENSAN LOS PROFESORES SOBRE SU ACTUACIÓN Y FORMACIÓN}

\section{RESUMEN}

La actuación del profesor en la atención educativa especializada (AEE) hay sido un grand desafio. El estúdio investigó lo que piensan los profesores de AEE sobre la formación docente, mas especificamente, la formación para actuar en el AEE. Se desarrolló un estudio de caso con profesores de salas multifuncionales (AEE) de escuelas públicas del municipio de Ouro Preto/Minas Gerais. El estudio evidencia que a pesar de las políticas nacionales para la inclusión en educación, los municipios no tienen desarrollado esas políticas a satisfacción. Se revela que la inversión pública en la formación del profesor ha sido mínimo obligando al profesor a buscar su formación de forma individual y solitaria. Es posible decir que, con mucho esfuerzo, ese profesor se hace professional a través de una formación fragmentada e personal.

Palabras clave: Inclusión en Educación. Atención Educativa Especializada. Formación docente.

\section{SPECIALIZED EDUCATIONAL ASSISTANCE: WHAT TEACHERS THINK ABOUT THEIR ACTION AND TRAINING}

\section{ABSTRACT}

The teacher's performance in specialized educational assistance has been a great challenge. This challenge led us to investigate what teachers think about the teacher's training to act in this assistance. Starting from the great challenge that has been the teacher's performance in the specialized educational assistance, the present study sought to investigate what teachers think about the teacher training to act in this assistance. A case study was developed with teachers who work in specialized classrooms in public schools in the city of Ouro Preto. The study shows that although there are national policies for inclusion in education, municipalities do not always develop these policies satisfactorily. It reveals that public investment in teacher training has been minimal and this forces the teacher to seek their training individually and solitary. It is possible to say that, with much effort, this teacher becomes professional, with a fragmented professional development.

Keywords: Inclusion in Education. Specialized Educational Assistance. Teacher Training.

Submetido em: 06 de dezembro de 2018 Aprovado em: 30 de abril de 2019 